\title{
In vitro antioxidant and free radical scavenging activity of different parts of Tabebuia pallida growing in Bangladesh
}

\author{
Md. Mahbubur Rahman', Md. Badrul Islam², Mohitosh Biswas ${ }^{1}$ and A. H. M. Khurshid Alam*
}

\begin{abstract}
Background: In humans, many diseases are associated with the accumulation of free radicals. Antioxidants can scavenge free radicals and minimize their impact. Therefore, the search for naturally occurring antioxidants of plant origin is imperative. Here, we aimed to investigate the antioxidant and free radical scavenging properties of methanolic extracts from Tabebuia pallida (T. pallida) stem bark (TPSB), root bark (TPRB), leaves (TPL), and flowers (TPF).
\end{abstract}

Methods: The antioxidant and free radical scavenging activity were determined by several standard methods using spectrophotomer. Total phenolic and flavonoid contents were estimated using Folin-Ciocalteu reagent and aluminum chloride colorimetric assay methods, respectively.

Results: Among the extracts, TPL showed the highest total antioxidant capacity followed by TPRB, TPF, and TPSB. Based on DPPH and hydroxyl radical scavenging activity, TPL showed strong scavenging activity (91.05 \pm 1.10 and $62.00 \pm 0.57$ ) with IC $C_{50}$ of $9.20 \pm 0.28$ and $46.00 \pm 2.84 \mu \mathrm{g} / \mathrm{mL}$, respectively when compared with standard BHT (IC $C_{50}$ of $7.00 \pm 0.25 \mu \mathrm{g} / \mathrm{mL})$ and $C A(75.00 \pm 0.14 \mu \mathrm{g} / \mathrm{mL})$. These results suggest that TPL had the highest radical scavenging activity among the extractives that closely resembled the standard's. In lipid peroxidation inhibition assay, TPL exhibited the most potent inhibitory activity $(83.18 \pm 2.12 \%)$ with $I C_{50}$ of $12.00 \pm 2.12 \mu \mathrm{g} / \mathrm{mL}$, which closely resembled standard $C A$ ( $\left(\mathrm{C}_{50}\right.$ of $\left.10.50 \pm 0.28 \mu \mathrm{g} / \mathrm{mL}\right)$. Also, the reducing capacity on ferrous ion was in the following order: TPL > TPRB > TF > TPSB. The phenolic and flavonoid contents of TPL were higher than other extractives. A positive correlation ( $p$ value $<0.001$ ) was observed between phenolic content and free radical ( $\mathrm{DPPH}$ and ${ }^{\circ} \mathrm{OH}$ ) scavenging efficiencies and lipid peroxidation inhibition activity.

Conclusion: Methanolic extract of T. pallida leaf is a potential source of natural antioxidants and serves as an effective free radical scavenger and/or inhibitor. Hence, T. pallida might be a good plant-based pharmaceutical product for several diseases caused by free radicals.

Keywords: Tabebuia pallida, Free radicals, Polyphenols, Antioxidant

\section{Background}

There is strong evidence that many dangerous pathophysiological processes, such as cancer, diabetes and cardiovascular and neurodegenerative diseases, are associated with the accumulation of free radicals [1-3]. A free radical is an atom or molecule that has an unpaired electron and

\footnotetext{
*Correspondence: khurshid.jaist@gmail.com

${ }^{1}$ Department of Pharmacy, University of Rajshahi, Rajshahi 6205, Bangladesh

Full list of author information is available at the end of the article
}

is therefore unstable. This unstable radical has the tendency to become stable through electron pairing with biological macromolecules such as proteins, lipids, and DNA in healthy human cells, thus causing protein and DNA damage [1]. Such radical-caused cell damage can become more widespread due to weakened cellular antioxidant defense systems. All biological systems have innate antioxidant defense mechanisms that remove damaged molecules, but these mechanisms can be inefficient. Therefore dietary intake of antioxidants is imperative to protect cells from damage caused by free radicals. 
Antioxidants are substances that prevent and stabilize the damage caused by free radicals by supplying electrons from antioxidants to these damage cells. Antioxidants also turn free radicals into waste by-products, which are eliminated from the body. Consumption of antioxidantenriched fruits and vegetables is known to lower the risk of several diseases caused by free radicals [4]. Such health benefits are mainly due to the presence of phytochemicals such as polyphenols, carotenoids, and vitamin $\mathrm{E}$ and $\mathrm{C}$ [5]. Although phenolic compounds are commonly found in both edible and in non edible herbs, cereals, fruits, vegetables, oils, spices, and other plant materials $[6,7]$, scientific information on the antioxidant properties of endemic plants is scare because the availability of endemic plants is limited to certain regions and only known by local populations. Therefore, the assessment of such properties remains an interesting and useful task, particularly to find promising sources of natural antioxidants for functional foods and/or nutraceuticals [7, 8].

Tabebuia palllida (commonly known as White trumpet tree), is one of the largest genera of the Bignoniaceae family distributed in central America, West India, and South America [9, 10]. To the best of our knowledge, there is no work investigating the phytochemical composition and biological activities of $T$. palllida. Therefore, we performed a detailed literature review of the Tabebuia genus. We found that Tabebuia has a variety of biological activities [9] and is recognized as a therapeutic alternative by rural or remote populations for the treatment of different diseases. Tabebuia rosea is used as an antipyretic, anti-inflammatory, antibacterial, antifungal, anti-cancer, and anti-diabetic agent [10-15]. Stem bark of $T$. avellanedae is used in the treatment of snake bites [10, 16]. Also, T. heterophylla, T. aurea, T. argentea and T. caraiba are used as anticancer, anti-inflammatory, and antimicrobial agents $[9,17]$.

The results of ethnobotanical and ethnopharmacological studies of different species of T. pallida indicate the potential use of these plants for the treatment of a large variety of diseases. Due to the increasing interest in the relationship between antioxidants and diseases, it is important to measure the overall antioxidant activity of $T$. pallida. Therefore, the objective of this study was to evaluate the antioxidant and free radical scavenging activity as well as polyphenol contents of methanolic extractives from different parts of T. pallida.

\section{Methods}

Plant collection

Leaves, flowers, stem and root barks of T. pallida were collected from Rajshahi University Campus, Rajshahi, Bangladesh on 11th May, 2013 and were identified by an expert taxonomist at the Department of Botany, University of Rajshahi, where a voucher specimen (Voucher No. MN-03) was deposited. Plant materials were then washed separately with fresh water to remove dirt and other contaminants, and were shade-dried for several days with occasional sun drying. The dried materials were ground into coarse powder by a grinding machine and the materials were stored at room temperature (RT) for future use.

\section{Preparation of the extract}

The extraction was performed according to Alam et al. [18]. About $500 \mathrm{~g}$ of each powdered plant materials was taken in four amber colored extraction bottles and soaked with $1.5 \mathrm{~L}$ of methanol. The sealed bottles were kept for 15 days with occasional shaking and stirring. The extracts were filtered separately through a fresh cotton plug and finally with Whatman No.1 filter papers. The filtrates were concentrated with a rotary evaporator (Bibby Sterlin Ltd, UK) under reduced pressure at $50{ }^{\circ} \mathrm{C}$ to afford $30,35,45$ and $40 \mathrm{~g}$ extract of leaves, flowers, stem and root barks extract, respectively.

\section{Chemicals}

1,1-diphenyl-2-picrylhydrazyl (DPPH), potassium ferricyanide, catechin (CA), ferrous ammonium sulphate, butylated hydroxytoluene (BHT), gallic acid (GA), ascorbic acid (AA), $\mathrm{AlCl}_{3}$, trichloro acetic acid (TCA), sodium phosphate, sodium nitrate, ammonium molybdate, sodium hydroxide, EDTA and $\mathrm{FeCl}_{3}$ were purchased from Sigma Chemical Co. (St. Louis, MO, USA); potassium chloride, potassium acetate, phosphate buffer, 2-deoxyD-ribose, thiobarbituric acid (TBA), $\mathrm{HCl}, \mathrm{H}_{2} \mathrm{SO}_{4}, \mathrm{H}_{2} \mathrm{O}_{2}$ were purchased from Sigma-Aldrich, folin-ciocalteus's phenol reagent and sodium carbonate were obtained from Merck (Dam-stadt, Germany).

\section{Determination of total phenolics}

Total phenolic contents in the extracts were determined by the modified Folin-Ciocalteu method described by Wolfe et al. [19]. An aliquot of the extract was mixed with $2 \mathrm{~mL}$ Folin-Ciocalteu reagent (previously diluted with water $1: 10 \mathrm{v} / \mathrm{v})$ and $2 \mathrm{~mL}(75 \mathrm{~g} / \mathrm{L})$ of sodium carbonate. The tubes were vortexed for $15 \mathrm{~s}$ and allowed to stand for $20 \mathrm{~min}$ at $25{ }^{\circ} \mathrm{C}$ for color development. Absorbance was then measured at $760 \mathrm{~nm} \mathrm{UV-spectrophotometer} \mathrm{(Shi-}$ madzu, USA). Samples of extract were evaluated at a final concentration of 0.1 and $0.15 \mathrm{mg} / \mathrm{mL}$. Total phenolic contents were expressed in terms of gallic acid equivalent, GAE (standard curve equation: $y=0.091 \times+0.167$, $\left.\mathrm{R}^{2}=0.994\right)$, mg of GA/g of dry extract. The experiment was repeated three times at each concentration. 


\section{Determination of total flavonoids}

Total flavonoids were estimated using aluminum chloride colorimetric assay described by Zhisen et al. [20]. To $0.5 \mathrm{~mL}$ of samples/standard, $150 \mu \mathrm{L}$ of $5 \%$ sodium nitrate and $2.5 \mathrm{~mL}$ of distilled water were added. After $5 \mathrm{~min}, 0.3 \mathrm{~mL}$ of $10 \% \mathrm{AlCl}_{3}$ was added. At $6 \mathrm{~min}, 1 \mathrm{~mL}$ of $0.001 \mathrm{M} \mathrm{NaOH}$ and $0.55 \mathrm{~mL}$ distilled water was added to the mixture and left at RT for $15 \mathrm{~min}$. Absorbance of the mixtures was measured at $510 \mathrm{~nm}$. Samples of extract were evaluated at a final concentration of 0.1 and $0.15 \mathrm{mg} / \mathrm{mL}$. Total flavonoid contents were expressed in terms of catechin equivalent, CAE (standard curve equation: $\left.\mathrm{y}=0.000 \times+0.001, \mathrm{R}^{2}=0.998\right), \mathrm{mg}$ of CA/g of dry extract. The experiment was repeated three times at each concentration.

\section{Determination of total antioxidant capacity}

Total antioxidant capacity (TAC) of samples was determined by the method reported by Prieto et al. [21]. The assay is based on the reduction of $\mathrm{Mo}(\mathrm{VI})$ to $\mathrm{Mo}(\mathrm{V})$ by samples and formation of green colored phosphate/ $\mathrm{Mo}(\mathrm{V})$ complex at acidic $\mathrm{pH}$. $0.5 \mathrm{~mL}$ of samples/standard at different concentrations $(12.5-150 \mu \mathrm{g} / \mathrm{mL})$ was mixed with $3 \mathrm{~mL}$ of reaction mixture containing $0.6 \mathrm{M}$ sulphuric acid, $28 \mathrm{mM}$ sodium phosphate and $1 \%$ ammonium molybdate into the test tubes. The test tubes were incubated at $95{ }^{\circ} \mathrm{C}$ for $10 \mathrm{~min}$ to complete the reaction. After cooling at RT, sample absorbance was measured at $695 \mathrm{~nm}$ using a spectrophotometer against a blank solution. CA was used as standard. A typical blank solution contained $3 \mathrm{~mL}$ of reaction mixture and the appropriate volume of the same solvent used for the samples/standard. The blank was incubated at $95{ }^{\circ} \mathrm{C}$ for $10 \mathrm{~min}$ and the absorbance was measured at $695 \mathrm{~nm}$. Increased absorbance of the reaction mixture indicates increased total antioxidant capacity. We used standard/samples at five different concentrations ranges from 12.5 to $150 \mu \mathrm{g} / \mathrm{mL}$ for each antioxidant assay. Concentrations were selected on the basis of trial and error to fit the range of concentration that can fully represent the rational change of antioxidant activity with the increasing concentration of the samples. Also, we assumed that such range of concentrations is useful for smooth calculation of $\mathrm{IC}_{50}$. The experiment was repeated three times at each concentration.

\section{Ferrous reducing antioxidant capacity assay}

The ferrous reducing antioxidant capacity (FRAC) of samples was evaluated by the method of Oyaizu [22]. The $\mathrm{Fe}^{2+}$ can be monitored by measuring the formation of Perl's Prussian blue at $700 \mathrm{~nm} .0 .25 \mathrm{~mL}$ samples/standard solution at different concentration $(12.5-150 \mu \mathrm{g} / \mathrm{mL})$,
$0.625 \mathrm{~mL}$ of potassium buffer $(0.2 \mathrm{M})$ and $0.625 \mathrm{~mL}$ of $1 \%$ potassium ferricyanide, $\left[\mathrm{K}_{3} \mathrm{Fe}(\mathrm{CN})_{6}\right]$ solution were added into the test tubes. The reaction mixtures were incubated for $20 \mathrm{~min}$ at $50{ }^{\circ} \mathrm{C}$ to complete the reaction. Then $0.625 \mathrm{~mL}$ of $10 \%$ trichloro acetic acid (TCA) solution was added into the test tubes. The total mixture was centrifuged at $3000 \mathrm{rpm}$ for $10 \mathrm{~min}$, after which $1.8 \mathrm{~mL}$ supernatant was withdrawn from the test tubes and mixed with $1.8 \mathrm{~mL}$ of distilled water and $0.36 \mathrm{~mL}$ of $0.1 \%$ ferric chloride $\left(\mathrm{FeCl}_{3}\right)$ solution. The absorbance of the solution was measured at $700 \mathrm{~nm}$ using a spectrophotometer against blank. A typical blank solution contained the same solution mixture without plant extracts/standard and was incubated under the identical conditions. The absorbance of the blank solution was measured at $700 \mathrm{~nm}$. Increased absorbance of the reaction mixture indicates increased reducing capacity. The experiment was repeated three times at each concentration.

\section{DPPH radical scavenging assay}

Free radical scavenging ability of the extracts was tested by DPPH radical scavenging assay as described by Blois [23] and Desmarchelier et al. [24]. The hydrogen atom donating ability of the plant extractives was determined by the decolorization of methanol solution of 2,2-diphenyl-1-picrylhydrazyl (DPPH). DPPH produces violet/ purple color in methanol solution and fades to shades of yellow color in the presence of antioxidants. A solution of $0.1 \mathrm{mM}$ DPPH in methanol was prepared, and $2.4 \mathrm{~mL}$ of this solution was mixed with $1.6 \mathrm{~mL}$ of extract in methanol at different concentrations $(12.5-150 \mu \mathrm{g} / \mathrm{mL})$. The reaction mixture was vortexed thoroughly and left in the dark at RT for $30 \mathrm{~min}$. The absorbance of the mixture was measured spectrophotometrically at $517 \mathrm{~nm}$. BHT was used as reference. Percentage DPPH radical scavenging activity was calculated by the following equation:

$\% \mathrm{DPPH}$ radical scavenging activity $=\left\{\left(\mathrm{A}_{0}-\mathrm{A}_{1}\right) / \mathrm{A}_{0}\right\} \times 100$

where $A_{0}$ is the absorbance of the control, and $A_{1}$ is the absorbance of the extractives/standard. Then \% of inhibition was plotted against concentration, and from the graph $\mathrm{IC}_{50}$ was calculated. The experiment was repeated three times at each concentration.

\section{Hydroxyl radical scavenging activity}

Hydroxyl radical scavenging activity of the extractives was determined by the method of Halliwell et al. [25]. Hydroxyl radical was generated by the $\mathrm{Fe}^{3+}$-ascorbate-EDTA- $\mathrm{H}_{2} \mathrm{O}_{2}$ system (Fenton reaction). The assay is based on the quantification of the 2-deoxy-D-ribose degradation product, which forms a pink chromogen upon heating with TBA at low $\mathrm{pH}$. The reaction mixture 
contained $0.8 \mathrm{~mL}$ of phosphate buffer solution $(50 \mathrm{mmol}$ $\left.\mathrm{L}^{-1}, \mathrm{pH} 7.4\right), 0.2 \mathrm{~mL}$ of extractives/standard at different concentration $(12.5-150 \mu \mathrm{g} / \mathrm{mL}), 0.2 \mathrm{~mL}$ of EDTA $\left(1.04 \mathrm{mmol} \mathrm{L}^{-1}\right), 0.2 \mathrm{~mL}$ of $\mathrm{FeCl}_{3}\left(1 \mathrm{mmol} \mathrm{L}^{-1}\right)$ and $0.2 \mathrm{~mL}$ of 2-deoxy-D-ribose $\left(28 \mathrm{mmol} \mathrm{L}^{-1}\right)$. The mixtures were kept in a water bath at $37^{\circ} \mathrm{C}$ and the reaction was started by adding $0.2 \mathrm{~mL}$ of ascorbic acid, AA $(2 \mathrm{mmol}$ $\left.\mathrm{L}^{-1}\right)$ and $0.2 \mathrm{~mL}$ of $\mathrm{H}_{2} \mathrm{O}_{2}\left(10 \mathrm{mmol} \mathrm{L}^{-1}\right)$. After incubation at $37^{\circ} \mathrm{C}$ for $1 \mathrm{~h}, 1.5 \mathrm{~mL}$ of cold thiobarbituric acid, TBA $\left(10 \mathrm{~g} \mathrm{~L}^{-1}\right)$ was added to the reaction mixture followed by $1.5 \mathrm{~mL}$ of $\mathrm{HCl}(25 \%)$. The mixture was heated at $100{ }^{\circ} \mathrm{C}$ for $15 \mathrm{~min}$ and then cooled down with water. The absorbance of solution was measured at $532 \mathrm{~nm}$ with a spectrophotometer. The hydroxyl radical scavenging capacity was evaluated with the inhibition of percentage of 2-deoxy-D-ribose oxidation on hydroxyl radicals. The percentage of hydroxyl radical scavenging activity was calculated according to the following formula:

$$
\begin{aligned}
& \% \text { hydroxyl radical scavenging activity } \\
& \quad=\left[A_{0}-\left(A_{1}-A_{2}\right] \times 100 / A_{0}\right.
\end{aligned}
$$

where $\mathrm{A}_{0}$ is the absorbance of the control without a sample. $A_{1}$ is the absorbance after adding the sample and 2-deoxy-D-ribose. $A_{2}$ is the absorbance of the sample without 2-deoxy-D-ribose. Then $\%$ of inhibition was plotted against concentration, and from the graph $\mathrm{IC}_{50}$ was calculated. The experiment was repeated three times at each concentration.

\section{Lipid peroxidation inhibition assay}

The lipid peroxidation inhibition assay was determined according to the method described by Haenen and Bast [26]. Protocol used in this study for the use of rat as animal model for lipid peroxidation inhibition assay was approved by the Institutional Animal, Medical Ethics, Biosafety and Biosecurity Committee (IAMEBBC) for Experimentations on Animal, Human, Microbes and Living Natural Sources (225/320-IAMEBBC/IBSc), Institute of Biological Sciences, University of Rajshahi, Bangladesh. Excised rat liver was homogenized in buffer and then centrifuged to obtain liposome. To make $10 \%$ liver homogenate, excised Wister rat liver (weight of $\sim 150 \mathrm{~g}$ ) was minced using glass Teflon homogenizer in ice cold phosphate buffered saline (50 mm, pH 7.4). The homogenate was centrifuged at $12,000 \mathrm{rpm}$ for $15 \mathrm{~min}$ at $4{ }^{\circ} \mathrm{C}$. The supernatant was used as liposome for in vitro lipid peroxidation assay. The process of homogenization and filtration was carried out in ice cold condition. Firstly, $0.5 \mathrm{~mL}$ of supernatant, $1 \mathrm{~mL}$ of $0.15 \mathrm{M} \mathrm{KCl}$, and $0.3 \mathrm{~mL}$ of extractives or standard at different concentrations $(12.5-150 \mu \mathrm{g} / \mathrm{mL})$ were mixed. Peroxidation was initiated by the addition of $300 \mu \mathrm{L}$ of $0.5 \mathrm{mM} \mathrm{FeCl}_{3}$. The mixture was incubated at $37{ }^{\circ} \mathrm{C}$ for $30 \mathrm{~min}$ and the reaction was stopped by adding $2 \mathrm{~mL}$ of ice-cold TBA-TCA-HCl-BHT solution. The TBA-TCA-HCl solution was prepared by dissolving $1.68 \mathrm{mg}$ TCA and $41.60 \mathrm{mg}$ TBA in $10 \mathrm{ml}$ of $0.125 \mathrm{M} \mathrm{HCl} 1 \mathrm{~mL}$ BHT solution $(1.5 \mathrm{mg} / \mathrm{mL}$ ethanol) was added to $10 \mathrm{~mL}$ TBA-TCA $\mathrm{HCl}$ solution. The reaction mixture was heated for $60 \mathrm{~min}$ at $90{ }^{\circ} \mathrm{C}$ and then cooled on ice and centrifuged at $3000 \mathrm{rpm}$ for $5 \mathrm{~min}$. The supernatants were removed and the intensity of the pink colored complex was measured using a spectrophotometer at $532 \mathrm{~nm}$. The degree of lipid peroxidation was assayed by estimating the TBARS (TBA-reactive substances) content. A control experiment was performed in the presence of distilled water without the extract. The percentage of lipid peroxidation inhibition in the samples was calculated using the following formula:

$$
\begin{aligned}
& \% \text { lipid peroxidation inhibition } \\
& \quad=\left[\left(\mathrm{A}_{0}-\mathrm{A}_{1}\right) / \mathrm{A}_{0}\right] \times 100
\end{aligned}
$$

where $A_{0}$ is the absorbance of the control (300 $\mu \mathrm{l}$ of distilled water), and $A_{1}$ is the absorbance of extractives/ standard. Then \% of inhibition was plotted against concentration, and from the graph $\mathrm{IC}_{50}$ was calculated. The experiment was performed in triplicate and repeated three times at each concentration.

\section{Statistical analysis}

All tests were carried out in triplicates. Data were presented as mean $\pm \mathrm{SD}$. To evaluate significant relationships between experimental parameters by correlation and regression analysis, the $\mathrm{F}$ - and $\mathrm{t}$-tests ( $\mathrm{p}$-value $<0.001$ ) were used. Free R-software version 2.15.1 (http://www.rproject.org/) and Microsoft Excel 2007 (Roselle, IL, USA) were used for the statistical and graphical evaluations.

\section{Results}

\section{Determination of TAC and FRAC}

The TAC and FRAC of methanolic extracts of different parts of T. Pallida are shown in Table 1. Methanolic extracts of different parts of T. Pallida showed considerable antioxidant activity when compared with standard CA. At the concentration of $100 \mu \mathrm{g} / \mathrm{mL}$, the absorbance of methanolic extracts of TPL, TPRB, TPSB, TPF and CA was in the range of $0.525 \pm 0.032-1.78 \pm 0.083$; while at $150 \mu \mathrm{g} / \mathrm{mL}$, the absorbance of methanolic extracts of TPL, TPRB, TPSB, TPF and CA was in the range of $0.648 \pm 0.030-2.267 \pm 0.041$. Increasing the extractives' concentration increased the total antioxidant activity.

The methanolic extracts of T. pallida showed moderate to high FRAC with increased concentration of the extracts. At $100 \mu \mathrm{g} / \mathrm{mL}$, the absorbance of methanolic extracts of TPL, TPRB, TPSB, TPF and AA was in the range of $0.289 \pm 0.057-3.108 \pm 0.069$; whereas at $150 \mu \mathrm{g} /$ $\mathrm{mL}$, the absorbance of methanolic extracts of TPL, TPRB, 
Table 1 Absorbance of TAC and FRAC of different parts (TPL, TPRB, TPSB and TPF) of T. pallida at two different concentrations $(n=3, X \pm S E M)$

\begin{tabular}{|c|c|c|c|c|}
\hline \multirow[t]{2}{*}{ Extractives } & \multicolumn{2}{|l|}{ TAC } & \multicolumn{2}{|l|}{ FRAC } \\
\hline & At $100 \mu \mathrm{g} / \mathrm{mL}$ & At $150 \mu \mathrm{g} / \mathrm{mL}$ & At $100 \mu \mathrm{g} / \mathrm{mL}$ & $\begin{array}{l}\text { At } 150 \mu \mathrm{g} / \\
\mathrm{mL}\end{array}$ \\
\hline TPL & $1.256 \pm 0.026^{a}$ & $1.625 \pm 0.010$ & $2.199 \pm 0.135$ & $2.914 \pm 0.100$ \\
\hline TPRB & $0.912 \pm 0.097$ & $1.150 \pm 0.073$ & $0.503 \pm 0.002$ & $0.741 \pm 0.030$ \\
\hline TPSB & $0.685 \pm 0.099$ & $0.836 \pm 0.063$ & $0.289 \pm 0.057$ & $0.484 \pm 0.028$ \\
\hline TPF & $0.525 \pm 0.032$ & $0.648 \pm 0.030$ & $0.454 \pm 0.029$ & $0.669 \pm 0.094$ \\
\hline$C A$ & $1.78 \pm 0.083$ & $2.267 \pm 0.041$ & - & - \\
\hline AA & - & - & $3.108 \pm 0.069$ & $3.223 \pm 0.087$ \\
\hline
\end{tabular}

TPL, TPRB, TPSB and TPF are representing as T. pallida leaf, root bark, stem bark and flower, respectively. AA and CA are representing as ascorbic acid and catechin, respectively

a Each value is the average of three analyses \pm standard deviation

TPSB, TPF and AA was in the range of $0.484 \pm 0.028-$ $3.223 \pm 0.087$. A higher absorbance indicates a higher reducing power. These results demonstrated that the methanolic extract of TPL possessed the highest TAC and FRAC among all other extractives, closely resembling that of standards CA and AA (Table 1).

\section{DPPH radical scavenging activity}

Figure 1a shows the free radical scavenging activity of the methanolic extracts of TPL, TPRB, TPSB, and TPF of T. pallida and standard BHT. Among the extractives, TPL possessed the highest activity. At a concentration of $100 \mu \mathrm{g} / \mathrm{mL}$, the scavenging activity of TPL, TPRB, TPSB, and TPF was $91.05 \pm 1.10,89.55 \pm 0.70,49.65 \pm 1.95$ and $55.85 \pm 0.30 \%$, respectively, whereas at the same concentration, the standard BHT was $96.45 \pm 0.41 \%$ (Fig. 1a). The $\mathrm{IC}_{50}$ of methanolic extracts of TPL, TPRB, TPSB, and TPF was $9.2 \pm 0.28,48.5 \pm 1.70$, $100 \pm 4.66$ and $86.5 \pm 1.04 \mu \mathrm{g} / \mathrm{mL}$, respectively.
The $\mathrm{IC}_{50}$ of BHT (standard) was $7.00 \pm 0.25 \mu \mathrm{g} / \mathrm{mL}$ (Fig. 1b). The free radical scavenging activity of different extracts and BHT was in the following order: $\mathrm{BHT}>\mathrm{TPL}>\mathrm{TPRB}>\mathrm{TPF}>\mathrm{TPSB}$.

\section{Hydroxyl radical scavenging activity}

The hydroxyl radical scavenging activity of the methanolic extracts of TPL, TPRB, TPSB, and TPF was dose dependent. Among the extracts, TPL had higher activity than that of the other extracts. At a concentration of $100 \mu \mathrm{g} / \mathrm{mL}$, the scavenging activity of TPL, TPRB, TPSB and TPF was $62.00 \pm 0.57$, $50.64 \pm 0.08,57.21 \pm 0.16$ and $50.70 \pm 0.33 \%$, respectively, whereas at the same concentration, CA's was $63.59 \pm 0.23 \%$ (Fig. 2a). The hydroxyl radical scavenging activity of TPL was approximately equal to that of $\mathrm{CA}$ (standard). The $\mathrm{IC}_{50}$ of TPL, TPRB, TPSB, TPF and CA was $46.00 \pm 2.84$, $97.00 \pm 0.86,67.5 \pm 1.25,96.5 \pm 1.28$ and $75.00 \pm 0.14 \mu \mathrm{g} /$ $\mathrm{mL}$, respectively, demonstrating that the inhibitory activity of TPL was higher than standard CA (Fig. 2b).
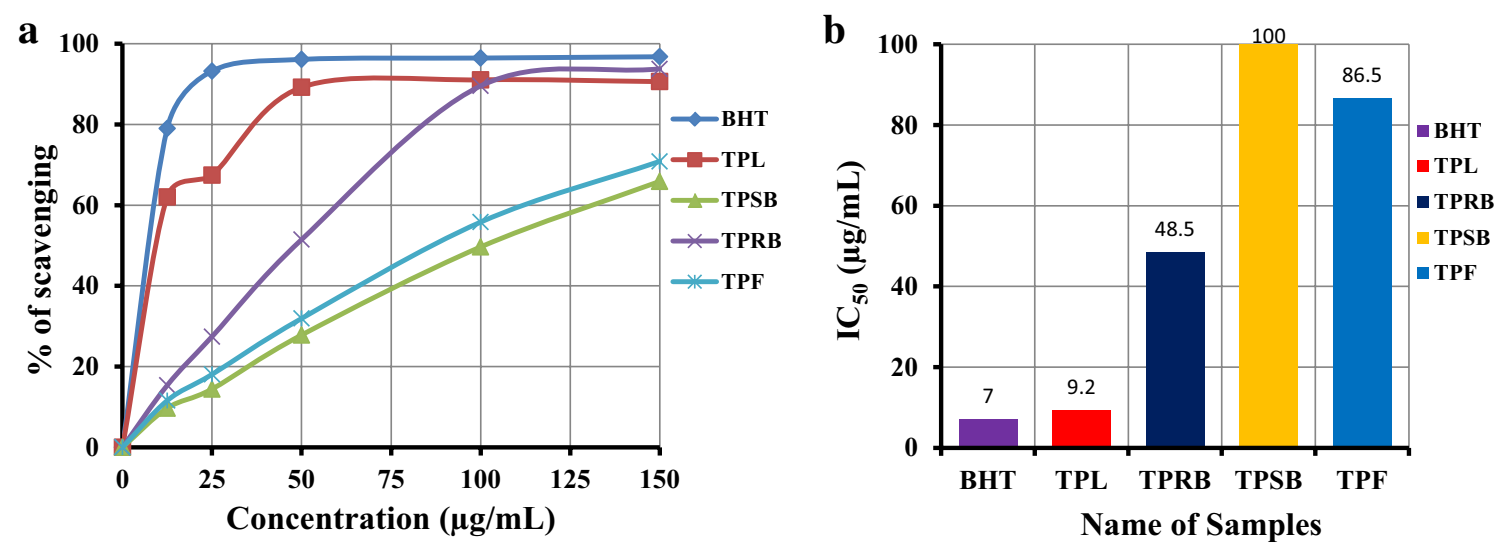

Fig. 1 Determination of a DPPH radical scavenging activity and $\mathbf{b} \mid \mathrm{C}_{50}$ of methanolic extractives (TPL, TPRB, TPSB and TPF) of T. pallida. All experiments were performed in triplicate. Data are expressed as mean $\pm S D(n=3, p<0.05)$ for all tested dosages 

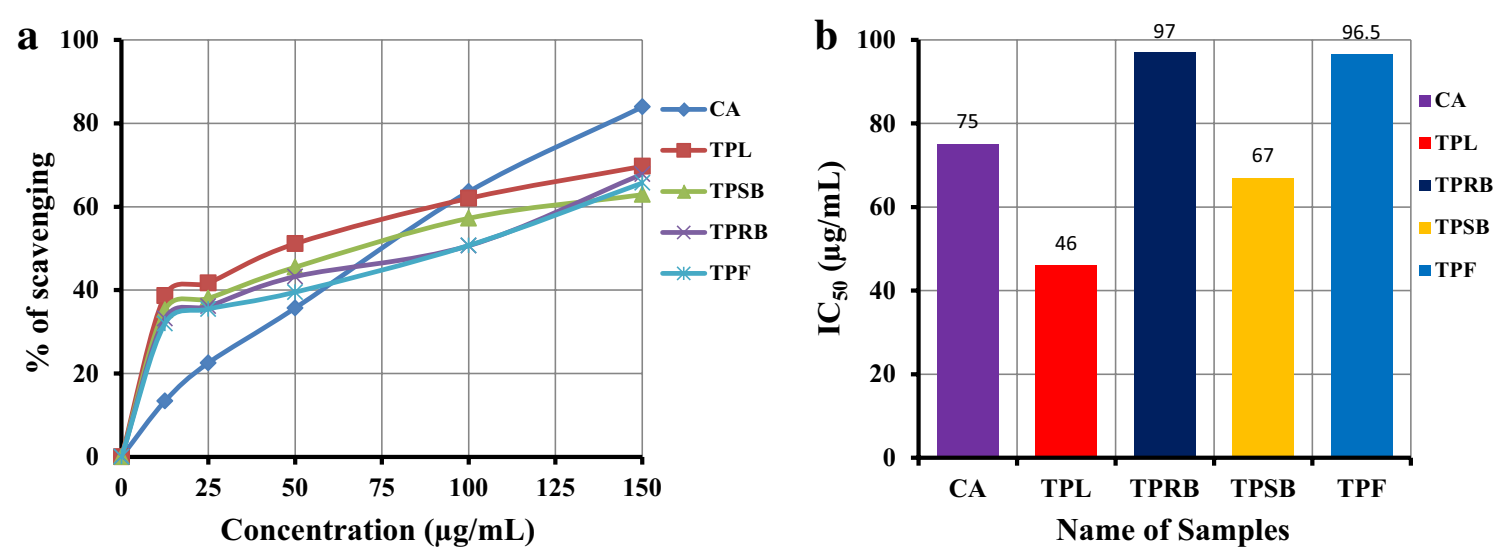

Fig. 2 Determination of $\mathbf{a}$ Hydroxyl radical scavenging activity and $\mathbf{b} \mid \mathrm{C}_{50}$ of methanolic extractives (TPL, TPRB, TPSB and TPF) of T. pallida plant. All experiments were performed in triplicate. Data are expressed as mean $\pm S D(n=3, p<0.05)$ for all tested dosages

\section{Lipid peroxidation inhibition assay}

The lipid peroxidation inhibition activity of TPL, TPRB, TPSB and TPF was compared with CA. At a concentration of $100 \mu \mathrm{g} / \mathrm{mL}$, the inhibitory activity of TPL, TPRB, TPSB and TPF was $83.18 \pm 0.33,74.56 \pm 0.45$, $70.53 \pm 0.55$ and $75.88 \pm 0.21 \%$, respectively; whereas that of the CA was $85.53 \pm 0.49 \%$ (Fig. 3a). The $\mathrm{IC}_{50}$ of TPL, TPRB, TPSB, TPF and CA were $12.00 \pm 0.14$, $16.00 \pm 0.57,25.50 \pm 0.50,13 \pm 1.08$ and $10.50 \pm 0.28$ $\mu \mathrm{g} / \mathrm{mL}$, respectively (Fig. $3 \mathrm{~b}$ ). TPL had higher inhibitory activity than other extracts and almost equal inhibitory activity to that of CA. A positive correlation ( $p$-value $<0.001$ ) of lipid peroxidation inhibition with free radical (DPPH and $\mathrm{OH}$ ) scavenging activities was observed.

\section{Total phenolic and flavonoid contents}

Table 2 shows the total polyphenols contents in the methanolic extracts of TPL, TPRB, TPSB, and TPF expressed as GAE and CAE. A standard curve for total phenolic and flavonoid contents is shown in Additional file 1: Figure S1 (A, B). A positive correlation $(p$-value $<0.001)$ of total phenolic content of the extractives with free radical (DPPH ${ }^{\prime}$ and $\mathrm{OH}$ ) scavenging efficiencies and \% of lipid peroxidation inhibition was observed (Additional file 2: Table S1).

\section{Discussion}

For assessment of antioxidant potential of endogenous compounds, a single assay method is not sufficient. Furthermore, different antioxidant assays vary in terms of assay principle and experimental conditions. For instant, some methods use organic radical producers e.g. DPPH and some use metal ions for oxidation e.g. FRAC assay technique. The time factor associated with their chemical reactions to produce free radicals by oxidation reaction also different from each other. Since the procedure and
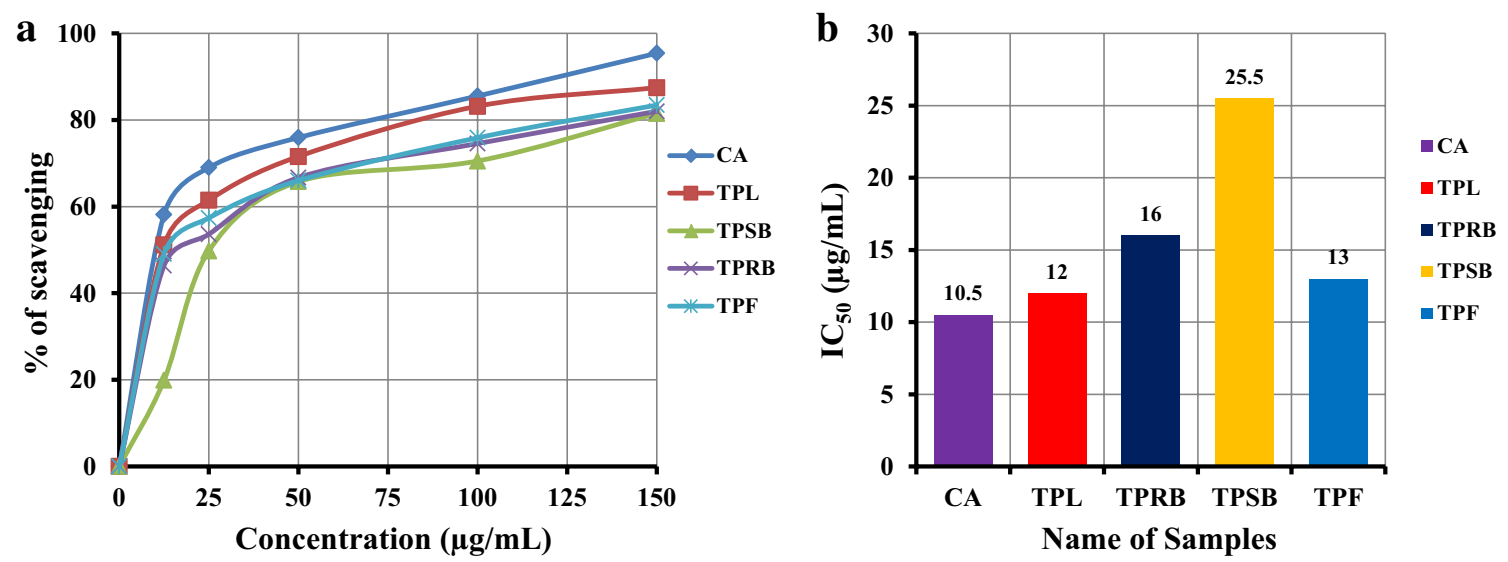

Fig. 3 Determination of a Lipid peroxidation inhibition activity and $\mathbf{b} I C_{50}$ of methanolic extractives (TPL, TPRB, TPSB and TPF) of T. pallida. All experiments were performed in triplicate. Data are expressed as mean $\pm S D(n=3, p<0.05)$ for all tested dosages 
Table 2 Polyphenol contents of the methanolic extracts of TPL, TPRB, TPSB, and TPF $(n=3, X \pm$ SEM)

\begin{tabular}{lrrr}
\hline Polyphenols & \multicolumn{1}{l}{ TPL } & TPRB & TPF \\
\hline Phenolics $^{a}$ & $56.19 \pm 1.11^{1}$ & $12.81 \pm 0.544$ & $15.93 \pm 0.974$ \\
Flavonoids $^{b}$ & $0.55 \pm 0.02$ & $0.16 \pm 0.016$ & $0.24 \pm 0.025$ \\
\hline
\end{tabular}

$a$ and $b$ expressed in terms of GAE and CAE, respectively (mg of GA and CA/g of dry extract, respectively)

${ }^{1}$ Each value is the average of three analyses \pm standard deviation

experimental conditions are different for different techniques, the various antioxidants are considered as a control for different assay techniques according to their rate and time of scavenging. In addition, antioxidants could be polar e.g. phenolics, flavanoids etc. or non-polar e.g. vitamin $\mathrm{E}$ in nature and they can act as radical scavenger by electron donating mechanism or by hydrogen donating mechanism. Therefore, different control antioxidants (e.g. BHT, AA, CA) were used for different antioxidant assays.

\section{Total antioxidant capacity and ferrous reducing antioxidant activity}

The antioxidant potential of the different parts of methanolic extracts of TPL, TPRB, TPSB, and TPF of T. pallida was estimated from their ability to reduce the reduction of Mo (VI) to Mo (V) by the antioxidant-enriched fractions and subsequent formation of a green phosphate/Mo (V) complex at acidic $\mathrm{pH}$. Antioxidant activity depends on the presence of its bio-active compounds mainly polyphenols, carotenoids, and vitamin $\mathrm{E}$ and $\mathrm{C}$ (27). This suggests that the concentration of the bioactive compounds present in the extract is important to showing antioxidant activity. Thus, higher concentration of extracts shows higher antioxidant activity. In this study, the reducing ability of the extractives was in the range of $0.648 \pm 0.030-1.625 \pm 0.010 \mu \mathrm{m}$ green phosphate/ Mo (V). All the extracts showed a good total antioxidant activity that increased with increasing concentration (Table 1). Our results comply with the data published elsewhere [27] and suggest that the antioxidant capacity can be attributed to the extractive's chemical composition and polyphenol contents.

Reducing power is also widely used in evaluating antioxidant activity of plant polyphenols. The reducing power is generally associated with the presence of reductants, which exert antioxidant action by breaking the free radical chains by donating a hydrogen atom. In this assay, the presence of reductants in the antioxidant sample reduces $\mathrm{Fe}^{3+} /$ ferricyanide complex to the $\mathrm{Fe}^{2+}$ / ferrous form. Thus, the reducing power of the sample can be monitored by measuring the formation of Perl's Prussian blue at $700 \mathrm{~nm}$ [27]. In this study, the iron reducing capacity of the methanolic extracts of TPL, TPRB, TPSB, and TPF was estimated from their ability to reduce the
$\mathrm{Fe}^{3+}$-ferricyanide complex to the ferrous form by donating an electron. The reducing ability of the extracts was in the range of $0.484 \pm 0.028-2.914 \pm 0.100 \mu \mathrm{m} \mathrm{Fe}(\mathrm{II}) / \mathrm{g}$ (Table 1). All the extracts showed a good reducing power capacity, which was concentration-dependent (Table 1). Our results are consistent with the data published previously [28]. Here, we assume that the antioxidant activity and reducing power capacity of the extracts was likely due to the presence of polyphenols, which can act as free radicals scavenger by donating an electron or hydrogen.

\section{DPPH radical scavenging activity}

The effect of antioxidants on DPPH is thought to be due to their hydrogen donating ability [29]. Radical scavenging activities are very important to prevent the deleterious role of free radicals in different diseases, including cancer. DPPH free radical scavenging is an accepted mechanism for screening the antioxidant activity of plant extracts. In the DPPH assay, violet color DPPH solution is reduced to yellow colored product, diphenylpicryl hydrazine, by the addition of the extract in a concentration dependent manner. This method has been used extensively to predict antioxidant activities because of the relatively short time required for analysis. Our results revealed that the methanolic extract of TPL had a similar free radical scavenging activity when compared with standard BHT (Fig. 1). Polyphenol contents and tocopherols scavenge the DPPH radicals by their hydrogen donating ability $[28,29]$. The results obtained in this study suggest that all the extracts from $T$. pallida showed radical scavenging activity by their electron transfer or hydrogen donating ability. Total polyphenols content and radical scavenging antioxidant activity are highly correlated [28].

\section{Hydroxyl radical scavenging activity}

The mutagenic capacity of free radicals is due to the direct interactions of hydroxyl radicals with DNA, resulting in DNA breakdown and therefore playing an important role in cancer formation [30]. Hydroxyl radicals are formed by incubating $\mathrm{Fe}^{+3}$ - EDTA premixture with ascorbic acid and $\mathrm{H}_{2} \mathrm{O}_{2}$ at $\mathrm{pH} 7.4$, causing 2-deoxyD-ribose degradation and generating a malondialdehyde (MDA)-like product. Addition of the methanolic extractives of TPL, TPRB, TPSB, and TPF to the reaction 
mixture removes hydroxyl radicals and prevents further damage. The extractives showed appreciable hydroxyl radical scavenging activity when compared with standard antioxidant, CA (Fig. 2), and could be served as anticancer agents by inhibiting the interaction of hydroxyl radicals with DNA. The ability of the extractives to quench hydroxyl radicals might directly relate to the prevention of lipid peroxidation.

\section{Lipid peroxidation inhibition assay}

Reactive oxygen species induce membrane damage by peroxiding lipid moieties, particularly the polyunsaturated fatty acids in a chain reaction known as lipid peroxidation [31]. The initial reaction generates a second radical, which can further react with a second macromolecule, generating chain reaction and causing cellular abnormalities. In vitro lipid peroxidation was induced in rat liver by ferric ion plus potassium chloride through $\mathrm{OH}$ radical generation by Fenton's reaction. The inhibition of lipid peroxidation is considered the most important index of antioxidant activity. Here, lipid peroxidation inhibition activity of TPL was higher than other extractives (Fig. 3). These results indicated that T. pallida can prevent cellular abnormalities caused by free radicals by breaking down the chain reactions responsible for lipid peroxidation. Thus, T. pallida is a good source of natural antioxidants and may be used to treat several diseases caused by free radicals.

\section{Total phenolic and flavonoid contents}

Total phenolic content of the extractives showed significant and strong positive correlation $(p$-value $<0.001)$ with free radical (DPPH' and $\mathrm{OH}$ ) scavenging efficiencies and \% of lipid peroxidation inhibition. The $\mathrm{R}^{2}$ values (correlation coefficients) between phenolic contents and free radical scavenging efficiencies and lipid peroxidation inhibition were shown in Additional file 2: Table S1. Our results are consistent with the data published previously [3, 32, 33]. Thus, the polyphenolic constituents of the extracts may be the major contributors to the antioxidant activity in free radical neutralization and lipid peroxidation inhibition.

\section{Conclusion}

Biologically active pure compound is better than crude extract. However, to get the overall view regarding the phytochemical composition and biological activities of any plant, it is important to pick the most potential part by investigating several parts (leaf, stem bark, root bark, fruits, flowers etc.) of that plant. Here, we examined different parts (root bark, stem bark, leaf and flower) of T. pallida and found that methanolic extract of T. pallida leaf, which contains large amounts of phenolic and flavonoid compounds, exhibited the highest antioxidant and free radical scavenging and also inhibited lipid peroxidation. A positive correlation ( $p$-value <0.001) was observed between phenolic content and free radical (DPPH' and ' $\mathrm{OH}$ ) scavenging efficiencies and lipid peroxidation inhibition activity. These in vitro assays indicate that T. pallida leaves are a significant source of natural antioxidants, which could help to prevent the progression of various diseases caused by free radicals, such as certain cancers. However, the components responsible for the antioxidative activity are currently unclear. Therefore, further investigation is needed to isolate and identify the antioxidant compounds present in the plant extract.

\section{Additional files}

Additional file 1: Figure S1. Standard curves for (A) phenolic and (B) flavonoid contents.

Additional file 2: Table S1. The $\mathrm{R}^{2}$ values (correlation coefficients) between phenolic contents and free radical scavenging efficiencies and lipid peroxidation inhibition.

\section{Abbreviations}

AA: ascorbic acid; CA: catechin; CAE: catechin equivalent; DPPH: 1,1-diphenyl2-picrylhydrazyl; EDTA: ethylenediamine tetraacetic acid; BHT: butylated hydroxytoluene; FRAC: ferrous reducing antioxidant capacity; GA: gallic acid; GAE: gallic acid equivalent; TAC: total antioxidant capacity; TCA: trichloro acetic acid; TBA: thiobarbituric acid; TPL: Tabebuia pallida leaves; TPF: Tabebuia pallida flower; TPRB: Tabebuia pallida root bark; TSB: Tabebuia pallida stem bark.

\section{Authors' contributions}

MMR: performed the study with analysis and acquisition of data. MB: helped analyze the data. MBI: helped to perform extraction of plant material and chemical tests. AHMKA: supervised the study design and drafted the manuscript. All authors read and approved the final manuscript.

\section{Author details}

${ }^{1}$ Department of Pharmacy, University of Rajshahi, Rajshahi 6205, Bangladesh. 2 BCSIR, Rajshahi 6205, Bangladesh.

\section{Acknowledgements}

The authors thank Mr John Vaughen, a researcher at Laboratory of Genetics, Graduate School of Biostudies, Kyoto University, Japan, for grammar correction and comments on the manuscript. The authors acknowledge the Bangladesh Council of Scientific and Industrial Research (BCSIR) and Department of Pharmacy, University of Rajshahi for financial support. We also thank Dr. AHM Mahabubur Rahman, Associate Professor, Department of Botany, University of Rajshahi, for the identification of the plant.

\section{Competing interests}

The authors declare that they have no competing interests.

Received: 20 May 2014 Accepted: 26 October 2015

Published online: 30 October 2015

\section{References}

1. Gilgun-Sherki Y, Rosenbaum Z, Melamed E, Offen D. Antioxidant therapy in acute central nervous system injury: current state. Pharmacol Rev. 2002:54:271-84.

2. Naskar S, Mazumder UK, Pramanik G, Bala A, Haldar PK, Islam A, et al. Comparative in vitro antioxidant activity of different parts of Cocos nucifera (Linn.) on reactive oxygen and nitrogen species. Int. J Pharm Pharm Sci. 2011;3:104-7. 
3. Islam S, Nasrin N, Khan MA, Hossain ASMS, Islam F, Khandokhar P, et al. Evaluation of antioxidant and anticancer properties of the seed extracts of Syzygium fruticosum Roxb. growing in Rajshahi, Bangladesh. BMC Complement Altern Med. 2013;13:142.

4. Hamid K, Saha MR, Urmi KF, Habib MR, Rahman MM. Screening of different parts of the plant Pandanus odorus for its antioxidant activity. Int J Appl Biol Pharm. 2010;1:1364-8.

5. Steinmetz KA, Potter JD. Vegetables, fruit, and cancer prevention: a review. J Am Diet Assoc. 1996;96:1027-39.

6. Kähkönen MP, Hopia Al, Vuorela HJ, Rauha JP, Pihlaja K, Kujala KS, et al. Antioxidant activity of plant extracts containing phenolic compounds. J Agric Food Chem. 1999;47:3954-62.

7. Miliauskas G, Venskutonis PR, Beek TAV. Screening of radical scavenging activity of some medicinal and aromatic plant extracts. Food Chem. 2004;85:231-7.

8. Balasundram N, Sundram K, Samman S. Phenolic compounds in plants and agri-industrial by products: antioxidant activity, occurrence, and potential uses. Food Chem. 2006;99:191-203.

9. Jiménez-González FJ, Veloza LA, Sepúlveda-Arias JC. Anti-infectious activity in plants of the genus Tabebuia. Univ Sci. 2013;18:257-67.

10. Kavya SK, Vijusha M, Rajani M, Hemamalini K, Sundari EGR. Screening of behavioural, muscle co-ordination \& anxiolytic activities of methanolic extract of Tabebuia rosea (Bertol). Asian J Pharm Clin Res. 2013;6:187-90.

11. Hemamalini $\mathrm{K}$, Lavanya $\mathrm{CH}$, Bhargav DA, Vasireddy DU. Anti-ulcer activity of methanolic extracts of Wattakaka volubilis and Tabebuia rosea in rats. Asian J Pharm Clin Res. 2012;5:242-6.

12. Oloyede GK, Oladosu IA, Shodia AF, Oloyade OO. Cytotoxic effects of Tabebuia rosea oils (leaf and stem bark). Arch Appl Sci Res. 2010;2:127-30.

13. Ramalakshmi S, Muthuchelian K. Analysis of bioactive constituents from the ethanolic leaf extract of Tabebuia rosea (Bertol.) DC by gas chromatography-mass spectrometry. Int J Chem Tech Res. 2011;3:1054-9.

14. Hemamalini K, Soujanya GL, Bhargav A, Vasireddy U. In vivo anticancer activity of Tabebuia rosea (Bertol) Dc. leaves on dalton's ascetic lymphoma in mice. Int J Pharm Sci Res. 2012;3:4496-502.

15. Joselin J, Brintha TSS, Florence AR, Jeeva S. Phytochemical evaluation of Bignoniaceae flowers. J Chem Pharm Res. 2013;5:106-11.

16. Gomes A, Das A, Sarkhel S, Mishra R, Mukherjee S, Bhattacharya S, et al Herbs and herbal constituents active against snake bite. Indian J Exp Biol. 2010;48:865-78.

17. Schmeda-Hirschmann G, Papastergiou F. Naphthoquinone derivatives and lignans from the Paraguayan crude drug "tayï pytá" (Tabebuia heptaphylla, Bignoniaceae). Z Naturforsch C. 2003;58:495-501.

18. Alam AHMK, Rahman MAA, Baki MA, Rashid MH, Bhuyan MSA, Sadik MG. Antidiarrhoeal principle of Achyranthes ferruginea Roxb. and their cytotoxic evaluation. Bangladesh Pharm J. 2002;12:1-4.

19. Wolfe K, Wu X, Liu RH. Antioxidant activity of apple peels. J Agric Food Chem. 2003;51:609-14.
20. Zhishen J, Mengcheng T, Jianming W. The determination of flavonoid contents in mulberry and their scavenging effects on superoxide radicals. Food Chem. 1999;64:555-9.

21. Prieto P, Pineda M, Aguilar M. Spectrophotometric quantitation of antioxidant capacity through the formation of a phosphomolybdenum complex: specific application to the determination of vitamin E. Anal Biochem. 1999;269:337-41.

22. Oyaizu M. Studies on products of browning reactions: antioxidant activities of products of browning reaction prepared from glucose amine. Jpn J Nutr. 1986;44:307-15.

23. Blois MS. Antioxidant determinations by the use of a stable free radical. Nature. 1958;181:1199-200.

24. Desmarchelier C, Bermudez MJN, Coussio J, Ciccia G, Boveris A. Antioxidant and prooxidant activities in aqueous extract of Argentine plants. Int J Pharmacogn. 1997:35:116-20.

25. Halliwell B, Gutteridge JMC. Free radicals in biology and medicine. Clarendon Press. 1989;3:617-783.

26. Haenen GR, Bast A. Protection against lipid peroxidation by a microsomal glutathione-dependent labile factor. FEBS Lett. 1983;159:24-8.

27. Oktay M, Gülçin I, Küfrevioglu OI. Determination of in vitro antioxidant activity of fennel (Foeniculum vulgare) seed extracts. LWT-Food Sci Technol. 2003;36:263-71

28. Huang D, Ou B, Prior RI. The chemistry behind antioxidant capacity assays. J Agric Food Chem. 2005;53:1841-56.

29. Baumann J, Wurn G, Bruchlausen FV. Prostaglandin synthetase inhibiting $\mathrm{O}_{2}$ radical scavenging properties of some flavonoids and related phenolic compounds. Deutsche Pharmakologische Gesellschaft abstracts of the 20th spring meeting, Naunyn-Schmiedebergs abstract no: R27 cited. Arc Pharmacol. 1979;307:R1-77.

30. Scully C. Oral cancer: new insights into pathogenesis. Dent Update. 1993;20:95-100

31. Klauning JE, Xu Y, Isenberg JS, Bachowski S, Kolaja KL, Jiang J, et al. The role of oxidative stress in chemical carcinogenesis. Environ Health Perspect. 1998;106:289-95.

32. Liu SC, Lin JT, Wang CK, Chen HY, Yang DJ. Antioxidant properties of various solvent extracts from lychee (Litchi chinenesis Sonn.) flowers. Food Chem. 2009;144:577-81.

33. Kedare BS, Singh RP. Genesis and development of DPPH method of antioxidant assay. J Food Sci Technol. 2011;48:412-22.

\section{Submit your next manuscript to BioMed Central and take full advantage of:}

- Convenient online submission

- Thorough peer review

- No space constraints or color figure charges

- Immediate publication on acceptance

- Inclusion in PubMed, CAS, Scopus and Google Scholar

- Research which is freely available for redistribution

Submit your manuscript at 